\title{
AfricArXiv
}

\section{Your COVID-19 Questions Answered}

Jamilu Ibrahim Nikau, Mohammed Auwal Ibrahim', Umar Ahmad², Mahmoud Bukar Maina ${ }^{3}$

${ }^{1}$ Ahmadu Bello University Zaria, Nigeria, ${ }^{2}$ Universiti Putra Malaysia,

${ }^{3}$ Federal Ministry of Health, Nigeria

Published on: Jul 02, 2020

DOI: $10.21428 / 3 b 2160 c d .121 b c 60 a$

License: Creative Commons Attribution 4.0 International License (CC-BY 4.0). 


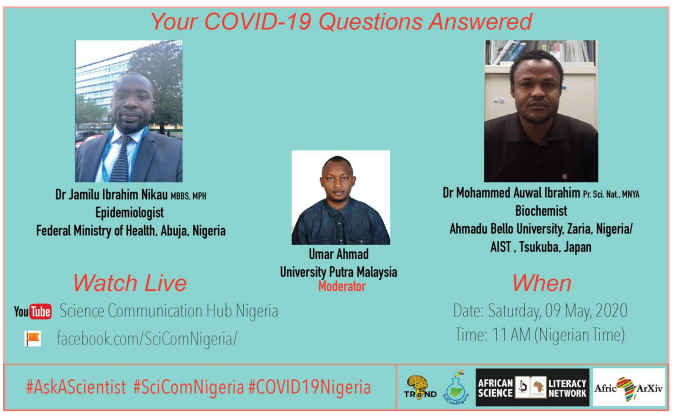

